\title{
Obstructive cholecystitis due to metastatic melanoma
}

\author{
D. G. Ostick \\ M.B., Ch.B., F.R.C.S. \\ M. T. HAQQANI* \\ M.B., B.S., M.R.C.Path. \\ Departments of Surgery and Pathology, University Hospital of South Manchester, Nell Lane, \\ West Didsbury, Manchester M20 8LR
}

\begin{abstract}
Summary
A patient with isolated metastases from cutaneous melanoma to the gall-bladder is reported. The patient presented clinically with obstructive cholecystitis. The course of melanoma is unpredictable and the possibility that an apparently unassociated condition is due to metastases should always be considered. Isolated metastases may respond well to radical surgery and reward the surgeon's efforts.
\end{abstract}

\section{Introduction}

The clinical course of malignant melanoma is unpredictable. Some patients with widespread metastases survive for many years but others with apparently localized primary tumours follow a rapid course to death. Post-mortem examinations disclose invariably that dissemination of the tumour is very extensive and the incidence of metastases in the gastro-intestinal tract is much higher than previously suspected (Das Gupta and Brasfield, 1964a). Metastases are found in the gall-bladder in about $15 \%$ of post-mortem examinations (Das Gupta and Brasfield, 1964b; Shimkin, Soloway and Jaffe, 1972) but very few patients have been described in whom they gave rise to symptoms. In this patient metastases from a cutaneous melanoma presented as obstructive cholecystitis.

\section{Case report}

A 56-year-old housewife was admitted as an emergency in March 1974 with 5 weeks" history of epigastric pain which radiated round both costal margins. Four days before admission she began to pass dark urine and then became jaundiced. In 1971 a malignant melanoma had been widely excised from the neck, and in 1972 cervical block dissection had been performed for metastases.

On examination she was slightly pyrexial $\left(37 \cdot 2^{\circ} \mathrm{C}\right)$ and jaundiced. She was tender in the right hypochondrium and there was an impression of an underlying mass.

\footnotetext{
* Present address: Consultant Pathologist, Walton Hospital, Liverpool.
}

Investigations showed haemoglobin $13.9 \mathrm{~g} / \mathrm{dl}$; WBC $4.3 \times 10^{\circ} / 1$; bilirubin $57 \mu \mathrm{mol} / 1(3.4 \mathrm{mg} / 100)$; alkaline phosphatase 670 i.u./1 (96 KA units); aspartate aminotransferase (AST) 79 i.u./l (79 units). A diagnosis of jaundice probably due to recurrent melanoma was made.

One week after admission the jaundice faded and biochemical tests showed the bilirubin to have fallen to $24 \mu \mathrm{mol} / 1$, alkaline phosphatase to $343 \mathrm{i} . \mathrm{u} . / 1$ and AST to 14 i.u./l. A liver scan using ${ }^{90 \mathrm{~m}} \mathrm{Tc}$ sulphur colloid showed no evidence of metastases but an oral cholecystogram disclosed a non-functioning gall bladder even after a double dose of sodium ipodate (Biloptin). The diagnosis was altered to obstructive cholecystitis due to gall-stones, and laparotomy was performed.

At operation, the gall-bladder was enlarged, in flamed and on palpation was firm and thickened, although there were no obvious stones. There was no metastatic melanoma in the liver or peritoneal cavity. Routine operative cholangiogram showed a normal biliary tract with no gall-stones, and cholecystectomy was performed. She was discharged home on the tenth postoperative day and remains well 1 year later. She has gained weight and there is no clinical evidence of further metastases; the liver scan remains normal and blood tests show haemoglobin $14.4 \mathrm{~g} / \mathrm{dl}$; bilirubin $14 \mu \mathrm{mol} / \mathrm{l}$, alkaline phosphatase 218 i.u./l and AST 12 i.u./l.

\section{Pathology}

Macroscopically, the gall-bladder was slightly distended and thick walled; it measured $8 \mathrm{~cm}$ in length and $4 \mathrm{~cm}$ in diameter at the fundus. On opening the viscus three black polypoid tumours were found but no gall-stones. The largest was in the fundus and measured $3.5 \times 2.5 \times 1.0 \mathrm{~cm}$, of the two smaller lesions, one was situated $1.5 \mathrm{~cm}$ proximally and measured $1.5 \times 1.0 \times 0.6 \mathrm{~cm}$, and the other $(0.7$ $\mathrm{cm}$ ) obstructed the cystic duct (Fig. 1). Each was pedunculated and attached by a narrow pedicle to the wall. Section of the pedicles disclosed that the 


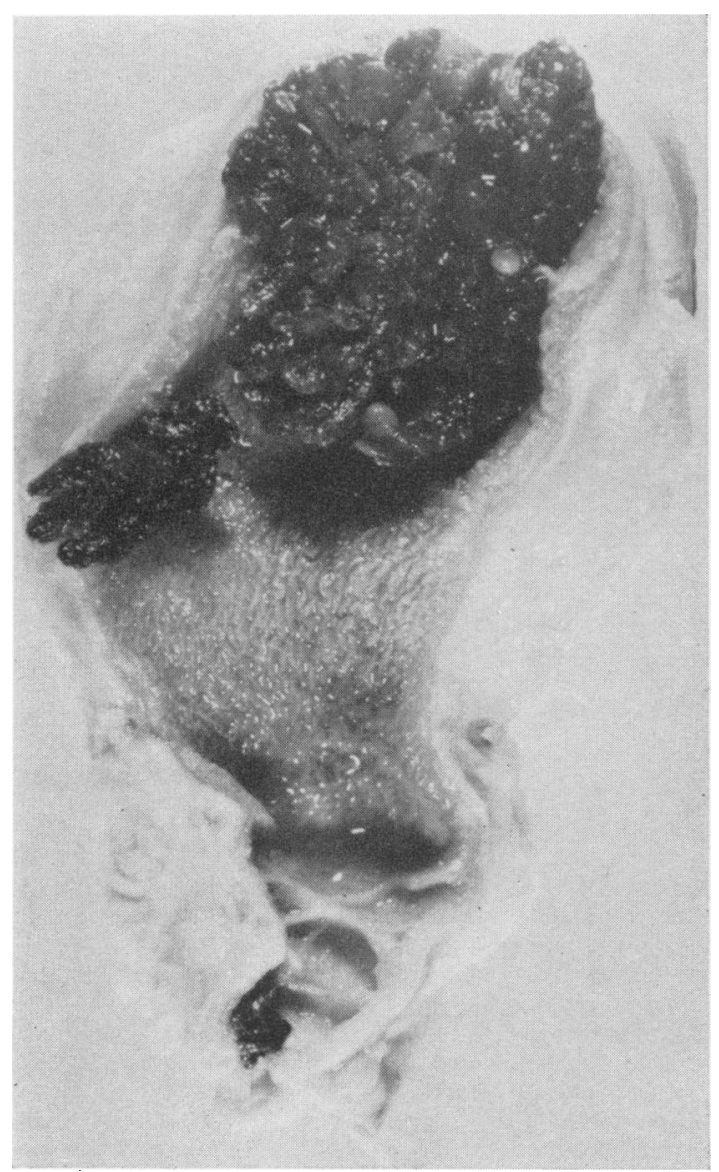

Fig. 1. The opened gall-bladder showing polypoid lesions. Note the small deposit in the cystic duct.

deposits were limited to the mucosa. The intervening mucosa showed changes of cholesterosis and the wall was $1.0 \mathrm{~cm}$ thick. The serosal surface over the tumour deposits and elsewhere was smooth. The regional lymph nodes were not enlarged.

Microscopically the tumours consisted of multiple papillae covered by orderly columnar epithelium and infiltrated by masses of cuboidal or polygonal cells with hyperchromatic nuclei, frequent mitotic figures and abundant melanin pigment (Fig. 2). Confluence and fusion of the papillae had resulted in the formation of pseudo-glandular structures. The fibrovascular pedicle was infiltrated by malignant cells which at the point of attachment extended to the muscularis. The appearances were those of metastatic melanoma. The remainder of the gall-bladder showed cholesterosis and chronic cholecystitis.

\section{Discussion}

In the terminal stages of melanoma, widespread dissemination is common and metastases are often found in the gall-bladder. In an extensive clinicopathological study, nineteen $(15 \%)$ of 125 patients had metastatic nodules in the gall-bladder (Das Gupta and Brasfield, 1964b). Mucosal lesions were found in seven of the patients but only two were polypoid; clinical review of the seven patients did not reveal any symptoms of gall-bladder disease. There are few reports of melanoma presenting clinically as acute gall-bladder disease; the diagnosis is usually made at laparotomy after radiology has shown gall-bladder disease. Polypoid lesions appearing as filling defects on cholecystography have been interpreted as gall-stones (Herrington, 1965; Zemlyn, 1966), or correctly diagnosed as polyps (Raffensperger, Brason and Triano, 1963; Shimkin et al., 1972).

Melanoma metastases may develop in a gallbladder which is already diseased and in the present patient's gall-bladder cholesterosis and chronic cholecystitis were found. Henriques (1955) found gall-stones and metastases in a patient with recurrent cholecystitis, and Simard et al. (1966) described melanoma developing in the gall-bladder of a 74year-old woman who had had two previous cholecystostomies for gall-stones. They proposed this was a primary melanoma of the gall-bladder and others have suggested likewise (Walsh, 1956; Jones, 1961). The pathology in these reports shows a remarkable gross and microscopic similarity to that described in the present report where the tumour was undoubtedly metastatic. Das Gupta, Brasfield and Paglia (1969) stated that primary melanoma of the gall-bladder must be extremely rare but metastases from cutaneous melanoma are not uncommon.

In the terminal stages, extensive dissemination occurs probably via the blood stream; the gallbladder metastases in the present case may have been blood-borne but it is possible that they were mucosal implants from the bile via the liver. This theory is supported by the superficial nature of the metastases and the abnormal liver function tests on admission, although there was no gross abnormality of the liver at operation. Liver biopsy was not taken and liver function tests have returned almost to normal.

This patient has presented twice with isolated metastases and these have been treated surgically, she remains well more than 2 years after the discovery of metastases. Hendrix (1969) reviewed 216 patients with melanoma and found thirty-five $(16 \%)$ had survived more than 5 years after the diagnosis of metastases. There were no clinical features of these patients which could help to assess prognosis but it was suggested that a proportion of patients with melanoma will live for a considerable period and efforts to eradicate metastases may be rewarding. 


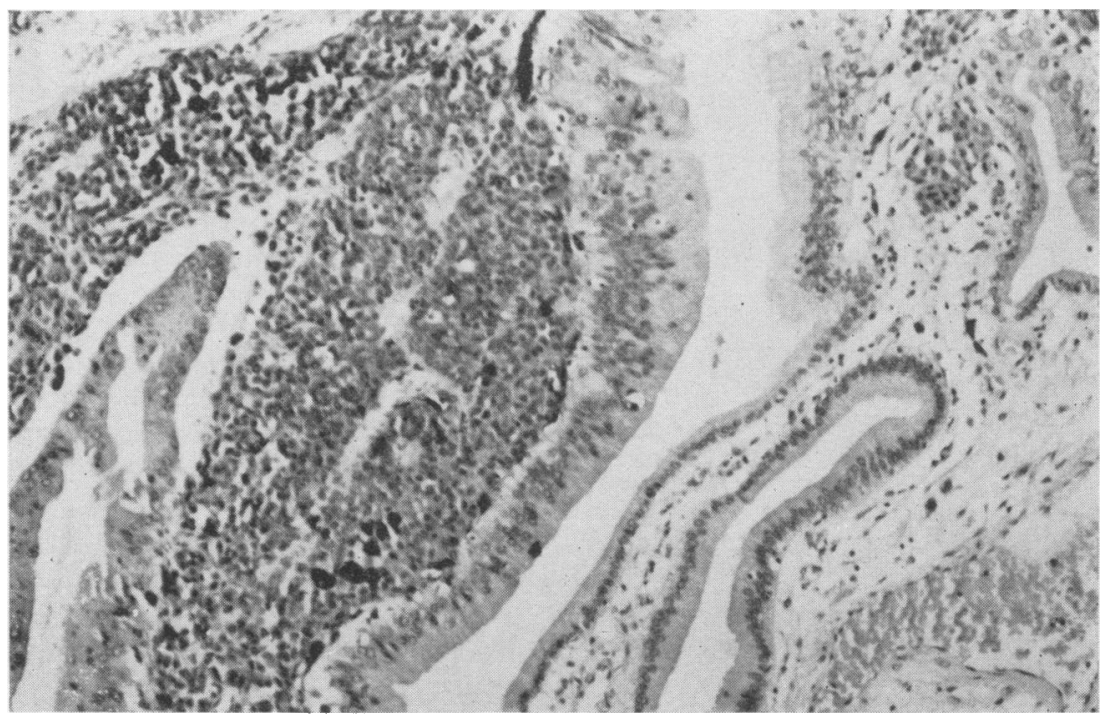

FIG. 2. Papillae covered by orderly columnar epithelium on the left infiltrated by malignant cells some of which contain melanin.

\section{Acknowledgments}

We would like to thank Mr D. J. Cowley and Mr F. Robinson for permission to publish this report.

\section{References}

Das Gupta, T.K. \& Brasfield, R.D. (1964a) Metastatic melanoma of the gastrointestinal tract. Archives of Surgery, 88, 969.

Das Gupta, T.K. \& Brasfield, R.D. (1964b) Metastatic melanoma. A clinico-pathological study. Cancer, 17, 1323.

Das Gupta, T.K., Brasfield, R.D. \& Paglia, M.A. (1969) Primary melanoma in unusual sites. Surgery, Gynecology and Obstetrics with International Abstracts of Surgery, 128, 841.

HeNDRIX, R.C. (1969) Unusual survival patterns of patients with metastatic melanoma. Cancer, 24, 574.

Henriques, C.Q. (1955) A case of secondary melanoma of the gall bladder presenting as acute cholecystitis. British Journal of Surgery, 42, 663.
Herrington, J.L. (1965) Metastatic malignant melanoma of the gall bladder masquerading as cholelithiasis. American Journal of Surgery, 109, 676.

JoNES, C.H. (1961) Malignant melanoma of the gall bladder: Journal of Pathology and Bacteriology, 81, 423.

Raffensperger, E.C., Brason, F.W. \& Triano, G. (1963) Primary melanoma of the gall bladder. American Journal. of Digestive Diseases, 8, 356.

Shimkin, P.M., Soloway, M.S. \& JAFfe, E. (1972) Metastatic melanoma of the gall bladder. American Journal of Radium Therapy and Nuclear Medicine, 116, 393.

Simard, C., George, P., Caulet, T. \& Diebold, J. (1966) Les mélanomes malins de la vésicule biliaire. Journal de Chirurgie (Paris), 92, 51.

WALSH, T.S. (1956) Primary melanoma of the gall bladder with cervical metastases and $14 \frac{1}{2}$ years survival. Cancer, 9, 518.

ZEMLYN, S. (1966) Metastatic melanoma of the gall bladder. Radiology, 87, 744. 